\title{
Criação de equipamentos de laboratório utilizando métodos alternativos para o uso no Ensino Médio
}

\author{
Kleviane Batista Gurgel; (Graduanda em Química na Universidade do Estado do RN- UERN) \\ Milton Alexandre Holanda Melo; (Graduando em Química na Universidade do Estado do RN- UERN) \\ Alexsandro Domingos de Oliveira; (Prof. do Estado do RN) \\ Antonio Gautier Farias Falconiere. (Prof. Do Departamento de Química da Universidade do RN- UERN)
}

\section{resumo:}

Nos dias atuais, os educadores de química de algumas escolas da rede pública enfrentam um grande desafio de realizar aulas práticas, devido as mesmas não apresentarem infraestrutura adequadas ou não terem os materiais necessários. O grande desinteresse dos educandos pela disciplina de química está diretamente ligada á falta de aulas experimentais, já que por meio delas a disciplina é apresentada de outra maneira, gerando uma outra metodologia de ensino na qual apresentam aulas mais dinâmicas e motivadoras para os estudantes. Na intenção de proporcionar um novo método de ensino na matéria de química na Escola Estadual Moreira Dias, a bolsista do Programa Institucional de Bolsa de Iniciação à Docência da Universidade do Estado do Rio Grande do Norte (PIBID/UERN), buscou uma maneira que pudesse suprir a necessidade das aulas práticas na escola e minimizar a desmotivação das turmas de ensino médio pela disciplina. O projeto visa a realização de aulas experimentais a partir de equipamentos alternativos, construídos por meio de materiais que apresentam baixo custo, além do reaproveitamento de materiais descartáveis ou não. A construção desses equipamentos primeiramente se deu por uma avaliação, juntamente com o supervisor do PIBID de química, de quais eram os equipamentos que tinham mais necessidades para a realização das aulas práticas nas turmas do ensino médio. Após esta avaliação, os equipamentos foram desenvolvidos pela bolsista juntamente com alguns alunos das turmas do $1^{\circ}$ e $2^{\circ}$ ano do ensino médio da escola citada. A aula teórico-prática foi realizada nas turmas referidas juntamente com os alunos que contribuíram para a construção, expondo para o restante da turma. Após a realização da exposição foi possível notar que os alunos demostraram interesse pela a aula, como também houve uma contribuição para o processo de aprendizagem dos mesmo. Atendendo assim todos os objetivos propostos pela bolsista no projeto.

pallavras-chave:

Laboratório Alternativo; Ensino da Química; Reaproveitamento; Equipamento de Laboratório. 


\section{Introdução}

O Programa Institucional de Bolsa de Iniciação à Docência da Universidade do Estado do Rio Grande do Norte (PIBID/UERN) incentiva os bolsistas a buscarem desenvolver projetos para aprimorar o processo de aprendizado dos alunos por meio de novas abordagens de ensino nas escolas que o PIBID atua.

Os alunos de ensino médio não apresentam, na maioria das vezes, um interesse pela disciplina de química, os quais consideram como uma matéria desinteressante e complicada, já que para eles atua somente na memorização de conceitos que por muitas vezes não se relaciona com a realidade. A quantidade de teoria, conceitos, fórmulas, repassadas aos alunos é muito grande para que os mesmos possam em pouco tempo assimilá-los e relacioná-los com a realidade em que se encontram (MORTIMER, 2000). Desta forma se faz necessário que está disciplina se relacione diretamente a teoria abordada com o cotidiano. Segundo Benite (2009), a maneira mais eficaz para se fazer esta ligação é através da realização de atividades práticas de laboratório.

A aula prática de laboratório é um desafio enfrentado por vários educadores de química, já que muitas escolas, principalmente as da rede pública não disponibilizam um local apropriado ou não têm os equipamentos necessários. Desta forma o projeto apresentado teve como objetivo suprir a necessidade de um laboratório de química dentro da Escola Estadual Moreira Dias, localizada no município de Mossoró - RN, para tentar aumentando assim o rendimento na aprendizagem dos alunos como também o interesse pela disciplina de química, visto que o docente de química da instituição tem uma grande dificuldade em ministrar aulas práticas devido a escola citada não apresentar um ambiente adequado e nem materiais necessários.

Os equipamentos laboratoriais foram desenvolvidos a partir de métodos alternativos e materiais reutilizados, os quais serão utilizados por meio de práticas que se relacionarão com o assunto abordado pelo professor em sala de aula.

\section{Objetivos}

\subsection{Geral}

- Criação de equipamentos de laboratório de química utilizando materiais de baixo custo visando uma melhoria na aprendizagem dos alunos para suprir as necessidades impostas.

\subsection{Especificos}

- Fazer uma avaliação dos equipamentos necessários;

- Produzir um Manual de Práticas o qual apresente as formas de utilização dos equipamentos criados a fim de serem utilizados em sala de aula;

- Apresentar os equipamentos e a utilização por meio de aulas experimentais;

- Incentivar os alunos à docência fazendo com que os mesmos, de forma espontânea, repassem os conhecimentos adquiridos através desse projeto para os demais.

\section{Metodologia}

Para a realização do projeto fez-se necessária a escolha de alguns alunos de cada turma com a ajuda do Professor de química da escola. Os alunos selecionados foram convocados para uma reunião onde foi 
apresentação projeto, seus objetivos e suas aplicações de acordo com cada turma e definir uma data para dar início às confecções dos equipamentos.

Para a elaboração dos equipamentos foi feita inicialmente uma avaliação junto com o professor relacionando os instrumentos de maior necessidade para a realização das práticas e adequando-os com as condições na qual a escola se encontra.

Após a avaliação, os utensílios criados ou adaptados foram:

- $\quad$ Aparelho de destilação.

Os materiais necessários foram:

- $\quad$ Garrafa Pet de 500ml (Condensador)

- $\quad$ Mangueira de equipo de soro (serpentina)

- $\quad$ Tampa da garrafa PET (tampa do condensador)

- $\quad$ Rolha (tampa do balão)

- 1 Lâmpada (balão de fundo redondo)

- 1 Lamparina

- $\quad$ Tubo de vidro (Passagem do vapor)

Além deste foi necessário

- $\quad$ Silicone;

- $\quad$ Cola quente

- $\quad$ Alicates .

Figura1 Sistema de destilação.

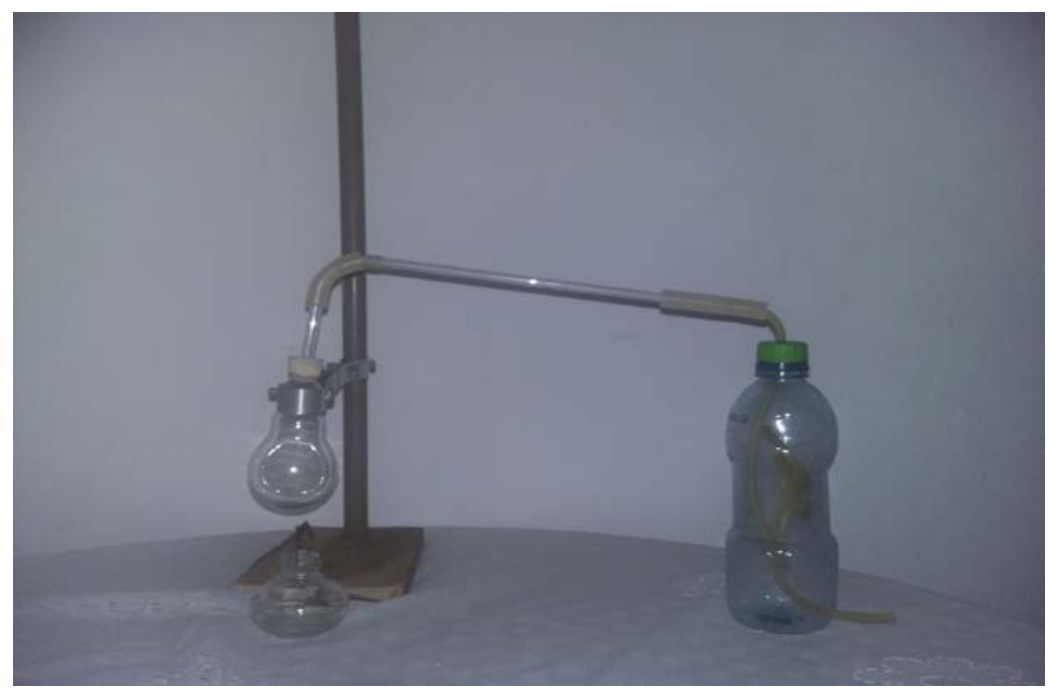

Fonte: Próprio autor

\section{- $\quad$ Becker .}

Foi adaptado por copos descartáveis de variados volumes. 
Figura 2 Becker 200mL

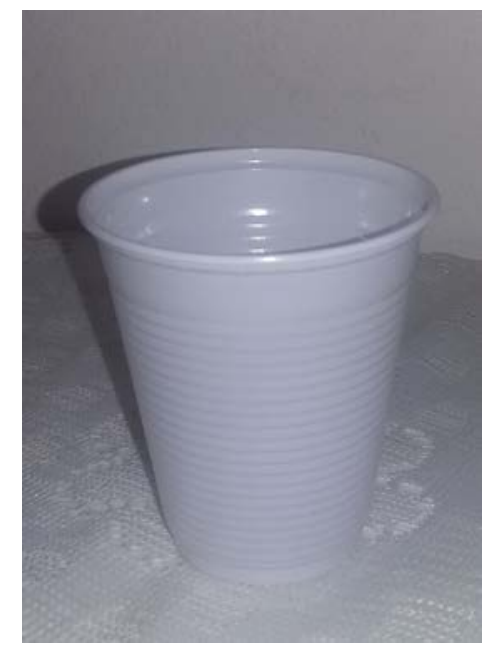

Fonte: Próprio autor

- $\quad$ Suporte universal.

Materiais necessários:

- $\quad$ Madeira ;

- $\quad$ Cano de PVC;

Figura 3Suporte Universal

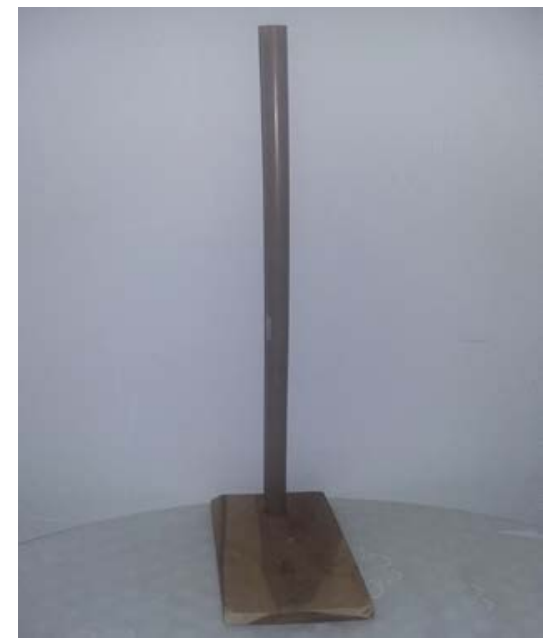

Fonte: Próprio autor

- $\quad$ Aparelhagem para a titulação.

Materiais necessários:

- $\quad$ Seringa de $25 \mathrm{~mL}$

- $\quad$ Equipo de soro; 
- $\quad$ Fita adesiva.

- $\quad$ Funil de bromo

- $\quad$ Garrafa PET de 500mL;

- $\quad$ Pregador de roupa;

- Garrote;

- $\quad$ Tubo de PVC;

Figura 4 Funil de

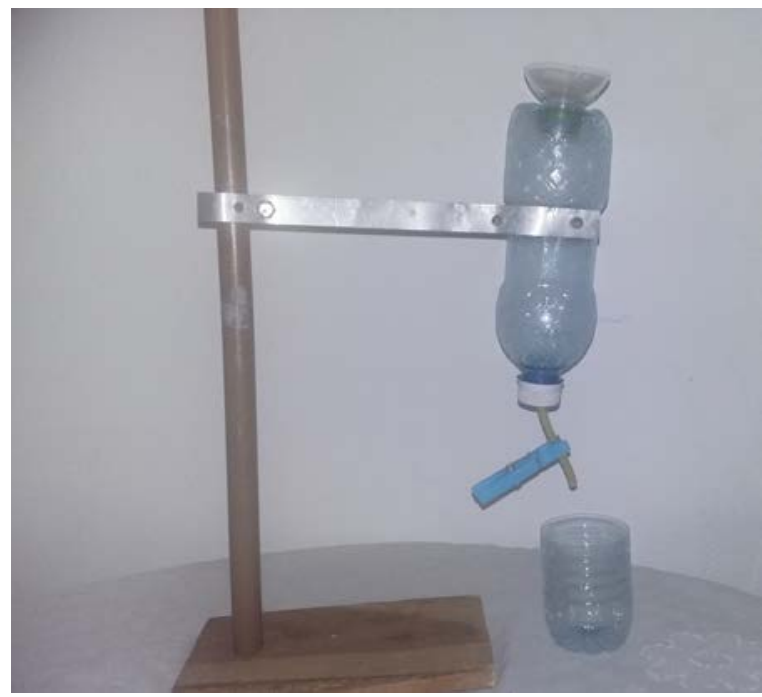

Bromo

Fonte: Próprio autor

Após a confecção dos equipamentos, foi discutido, junto com o professor, maneiras de aplicação na sala de aula. Assim foi indicada a apresentação dos equipamentos por meio de uma aula teórico-prática com a presença dos alunos escolhidos.

\section{Resultados e discussões}

O projeto desenvolvido na Escola Estadual Moreira Dias, mostrou uma evolução, tanto no comportamento e interesse dos alunos como também no processo de aprendizagem, pois em relação ao último quesito mencionando foi possível confirmar através de atividade pós pratica contendo perguntas sobre o assunto abordado anteriormente, na qual realizada ao término da aula teóricoprática.

A confecção dos equipamentos foi realizada a partir de uma avaliação, levando em conta a necessidade e os materiais necessários, os quais foram utilizados materiais de baixo custo e alguns

Foi adaptadas práticas laboratoriais de química, que pudessem ser realizadas com os equipamentos construídos e foram colocadas em caderno de laboratório onde continham práticas de turmas de $1^{\circ}$ ao $3^{\circ}$ ano do ensino médio.

Nas turmas de primeiro ano do ensino médio foram aplicadas as práticas de separação de misturas e de ácidos e bases, fazendo uso dos equipamentos de destilação, funil de bromo, béquer e com materiais de baixo custo e fácil acesso,

Já no segundo ano, a aula teórico-prática sobre a catálise da $\mathrm{H}_{2} \mathrm{O}_{2}$, onde foi utilizados copos descartáveis que substituíram o uso dos béqueres. 


\section{Conclusões}

Diante dos objetivos propostos e resultados que foram obtidos, pode-se concluir que o projeto realizado alcançou seus objetivos e permitiu que a partir da aula teórico-prática, proporcionar uma nova metodologia que não era abordada no ambiente escolar citado. A experiência desta nova metodologia, possibilitou uma aula mais dinâmica, fazendo com o que os conceitos abordados fossem fixados de maneira mais fácil, aumentando o rendimento na aprendizagem dos alunos.

As aparelhagens confeccionadas não são adequadas para resultados quantitativos, mas apresentam resultados satisfatórios em práticas de nível de ensino médio.

\section{Laboratory equipment creation using alternative methods for use in high school}

Albstract:Nowadays the chemistry educators from some public schools face a major challenge to conduct practical classes, because the schools do not provide adequate infrastructure or do not have the necessary materials. The biggest lack of interest of students for the discipline of chemistry, is directly linked to the lack of experimental classes, since through it the discipline is shown in other manner, creating another teaching methodology in which is presented dynamic and motivating classes for students. In an attempt to provide a new method of teaching in the field of chemistry at the Escola Estadual Moreira Dias, a colleger of the Programa Institucional de Bolsa de Iniciação à Docência of Universidade do Estado do Rio Grande do Norte (PIBID/UERN), sought a manner that would supply the need of practical classes at school and minimize the demotivation of high school classes for discipline. The project aims the achievement experimental lessons from alternative devices, constructed with materials that have a low cost in addition to the reuse of disposables materials or not. The construction of this equipment first was given by an assessment along with PIBID supervisor of chemistry which were the equipment that had more needs to carry out practical classes in high school classes, after this evaluation the equipment were developed by colleger along with some students of the classes of 1st and 2nd year of the mentioned high school. The theorical-practical class was held in the classes mentioned along with students who contributed to the construction exposing with the rest of the class, after the completion of exposure it was noticeable that students showed interest in the class, as there was also a contribution to the learning process of the same. Thus meeting all the goals proposed by the grantee in the project.

Keywords: Alternative laboratory; Teaching of Chemistry; reuse; Laboratory equipment.

\section{Referências bibliográficas}

SANTOS, Hugnéia C.; NDIAYE, Eliane A.. Materiais alternativos para utilização em labiratório. $2^{\circ}$ ed. São Paulo: Scipione, 1995.

NASCIMENTO, K. A.; REZENDE Y. F. G.; IZARIAS, N. S.. Construção de laboratório alternativo de química. Rio de Janeiro. 2013.

BENITE, Anna M. Canavarro; et al. Formação de Professores de Ciências em Rede Social: Uma Perspectiva Dialógica na Educação Inclusiva. Revista Brasileira de Pesquisa em Educação em Ciências Vol. 9, No 3, 2009 